\title{
SOCIALIZAÇÃO ÉTNICO-RACIAL DE CRIANÇAS NA CRECHE DE UMA COMUNIDADE REMANESCENTE DE QUILOMBOLAS
}

\author{
Pedro Neto Oliveira de Aquino \\ Silvia Helena Vieira Cruz.
}

\section{Resumo}

A presente pesquisa analisou as interações com colegas de turma vivenciadas por crianças negras remanescentes de quilombolas que frequentam creche na própria comunidade, com foco nas implicações de possíveis processos de identificação étnico-racial nessas interações. O procedimento utilizado para a construção dos dados foi a observação participante. A análise indica que as interações entre as crianças pareciam não sofrer implicações das diferenças de cor de pele, tipo de cabelo ou por outras marcas fenotípicas das crianças negras, o que parece decorrer do fato de as possibilidades de identificar essas diferenças e atribuir qualidades a elas ainda estarem em desenvolvimento, como processos de percepção e significação da realidade, e das experiências que elas viveram até então, tanto na instituição, como nas famílias, não terem sido marcantes para dar um forte colorido a essas diferenças. As relações afetivas foi o que pareceu ser considerado nas interações vivenciadas no coletivo investigado.

Palavras-chave: relações étnico-raciais; crianças negras; creche.

\section{ETHNIC-RACIAL SOCIALIZATION OF CHILDREN IN THE DAYCARE OF A DESCENDING FROM QUILOMBOLA COMMUNITY}

\begin{abstract}
This research analyzed the interactions with classmates experienced by black children remnant from quilombolas who attend nursery school on their own community, focusing on the implications of possible processes of ethnic-racial identification in these interactions. The utilized procedure for data construction was participant observation. The analysis indicates that the interactions among the children did not seem to suffer the implications of the differences in their skin color, hair style or other phenotypic marks of black children, what it seems to occur due to the fact that the possibilities of identifying these differences and attributing qualities to them, are still in development, as the processes of perception and significance of the reality, and from experiences lived by the children thus far, either at school or on their family environment, have not been significant enough to impact their perception of these differences. Affective relationships were what seemed to be considered important in the interactions experienced in the investigated collective. Keywords: ethnic-racial relationships; black children; nursery.
\end{abstract}

\section{SOCIALIZACIÓN ÉTNICO-RACIAL DE NIÑOS EN LA GUARDERÍA DE UNA COMUNIDAD DESCENDIENTE DE QUILOMBOLAS}

Resumen

Esta investigación analizó las interacciones con los compañeros de clase experimentados por los niños negros de remanentes quilombolas, que asisten a guardería infantil en su propia comunidad, centrándose en las implicaciones de los posibles procesos de identificación étnico-racial en estas interacciones. El procedimiento utilizado para construir los datos fue la observación participante. El análisis indica que las interacciones entre los niños no parecen sufrir las implicaciones de las diferencias en el color de la piel, el tipo de cabello u otras marcas fenotípicas de los niños negros, que parece derivarse del hecho de que las posibilidades de identificar estas diferencias y atribuirles cualidades aún están en desarrollo, como procesos de percepción y de significación de la realidad, y de las experiencias que han tenido hasta ahora, tanto en la institución, como en las familias, no han sido significativas para dar un color fuerte a estas diferencias. Las 
relaciones afectivas fue lo que pareció ser considerado en las interacciones experimentadas en el colectivo investigado.

Palabras clave: relaciones étnico-raciales; niños negros; guardería infantil.

\section{INTRODUÇÃO}

De acordo com Corsaro (2011), dois conceitos são fundamentais para a nova Sociologia da Infância. O primeiro refere-se à visão das crianças como agentes sociais que produzem cultura com características específicas e exclusivas da infância, ao mesmo tempo em que contribuem para a produção das sociedades adultas. O segundo conceito, a infância como uma categoria estrutural, afirma que esse "[...] período socialmente construído em que as crianças vivem suas vidas" (CORSARO, 2011, p. 15) é marcado pelas mesmas variáveis sociais que os outros grupos geracionais (adolescência, juventude, idade adulta e velhice), por exemplo, a classe social e o grupo étnico-racial ao qual pertence.

Essa criança concreta, situada social e historicamente, vive simultaneamente os processos de apropriação da realidade, através da socialização, e de construção da sua identidade. Para a Sociologia, o conceito de identidade precisa ser relacionado ao conceito de socialização. Nas palavras de Tap e Kerbel (apud MEDEIROS, 2002, p. 81), “[...] a construção da identidade pessoal não pode ser entendida se não a recolocamos dentro do jogo do processo de socialização".

Berger e Luckmann (1974, p. 173-174) afirmam que a socialização é o processo ontogenético pelo qual se realiza a interiorização, isto é, "[...] a apreensão ou interpretação imediata de um acontecimento objetivo como dotado de sentido". A socialização primária acontece através de pessoas significativas e em situações carregadas de emoção. Os autores consideram que:

A criança absorve os papéis e as atitudes de outros significativos, isto é, interioriza-os tornando-os seus. Por meio desta identificação com outros significativos a criança torna-se capaz de identificar a si mesma, de adquirir uma identidade subjetivamente coerente e plausível [...] A apropriação subjetiva da identidade e apropriação subjetiva do mundo social são apenas aspectos diferentes do mesmo processo de interiorização, mediatizados pelos mesmos outros significativos. (BERGER, LUCKMANN, 1974, p. 176-178, grifos dos autores).

Medeiros (2002, p. 85) sintetiza o processo de construção da identidade afirmando-o como uma "[...] representação simbólica da pessoa que é elaborada por um grupo social, que pode ser a família, a escola, a sociedade, o grupo de pertencimento etc.”. Na contramão de concepções clássicas, nas quais os sujeitos eram vistos submetendo-se passivamente à socialização, autores como Corsaro (2011) e Sarmento (2008) defendem a ideia de que a socialização é um processo criativo de apropriação, no qual a criança reinventa e reproduz a cultura de forma interpretativa. Mesmo as bem pequenas, elas atribuem ativamente significados às suas experiências.

Se considerarmos a socialização na infância a partir dessa abordagem interpretativa (CORSARO, 2011), não surpreende que as crianças pequenas incorporem as representações presentes na sociedade e passem a atentar para o que é socialmente valorizado ou não. É vivendo as suas infâncias, nas relações, no corpo, linguagens e práticas cotidianas que elas conhecem o mundo, as pessoas e a si mesmas.

Para Dubar (1991 apud MEDEIROS, 2002), a socialização é o que ele chama de uma transação objetiva, enquanto a interiorização seria uma transação subjetiva do processo de construção da identidade. Nessa perspectiva, a identidade é uma "[...] representação simbólica da pessoa, elaborada através do outro", construída num processo de socializações sucessivas, que acontecem na família, na escola etc. Sendo assim, um elemento importante da identidade da pessoa é a identidade étnicoracial. 
Socialização e identidade são conceitos que permeiam a discussão sobre relações étnicoraciais na infância, mas, há outros, como pertencimento étnico-racial, conceituado por Trinidad (2012, p. 122) como "[...] o conhecimento que a pessoa tem sobre si e sobre sua pertença como membro de um grupo com o qual compartilha, por exemplo, pensamentos, percepções, sentimentos e comportamentos". Observamos nessa compreensão duas dimensões, a individualidade e a coletividade, mas há, também, uma terceira dimensão presente na construção do pertencimento étnico-racial, a dimensão política, essencial, pois se reconhecer negro em uma sociedade marcada pela discriminação e pelo preconceito racial é, sobretudo, uma construção de caráter político (SILVA, 2015).

A mesma autora, em publicação posterior, apresenta um outro termo, que nos parece estar mais adequado aos processos vividos na infância — identificaşão étnico-racial. Para Trinidad (2016, p. 3), no Brasil, a identificaşão étnico-racial configura-se como um sistema complexo, ambíguo e fluido, resultante de:

[um] processo sofisticado de combinação de elementos da aparência - cor da pele, traços corporais (formato do nariz e dos lábios, tipo do cabelo), origem regional e social. Ou seja, ele resulta da "aparência geral", composta pela combinação entre o estilo de vida, o grau de instrução, a renda, o estilo em matéria de moda (penteado, tipo de roupa usado, marca de carro possuída) e até mesmo a simpatia ou a antipatia da pessoa em questão' ${ }^{1}$.

$\mathrm{Na}$ primeira infância, a criança, pelo seu pouco tempo na sociedade, ainda não viveu experiências suficientes para produzir uma noção estável de si como ser individual e coletivo (como é próprio do conceito de pertencimento), estando ainda construindo uma imagem de si em relação aos (e com) os outros. Como afirma Wallon (1995, p. 29) "[...] não somente porque o número de ocasiões oferecidas a ela e as experiências pelas quais ela passou permanecem muito restritas para poder gravar nela disposições particulares, mas, também em razão da descontinuidade essencial que se observa em seu comportamento". Esse autor acredita que a criança (aproximadamente até os seis anos) não entra em contato com o mundo social por meio de categorias nas quais classifica as pessoas para depois incluí-las nesses blocos: "[...] inicialmente as qualidades das coisas combinam-se com cada uma particularmente, sem poder servir para arrumá-las por comparação sistemática" (WALLON, 2007, p. 167).

A partir dessa compreensão do pensamento infantil, supomos que é possível às crianças por volta dos três anos, enfocadas nesse estudo, desenvolverem processos de identificação de elementos da aparência das pessoas (como os traços fenotípicos próprios dos negros) e combinação destes com os sentimentos / emoções em relação a pessoas concretas com as quais convivem. Isso ajuda a entender por que, como afirma Bento (2012, p. 101), mesmo "[...] em idade tão tenra, as crianças podem estar [...] ligadas às dimensões de fenótipos bem como aos valores que informam essas dimensões". Assim, experiências contínuas de discriminação étnico-racial contra si ou outros indivíduos negros contribuem para o comprometimento da imagem que a criança negra constrói de si e deste grupo étnico-racial.

Resultados de pesquisas sintetizados por Trinidad (2016, p. 4), realizadas nos Estados Unidos desde a década de 1940, acerca da identificação étnico-racial entre crianças pequenas, apontam nessa mesma direção:

\footnotetext{
1 Vale ressaltar que, nessa publicação, a autora usa os termos identificação e pertencimento étnico-racial como semelhantes, por exemplo, no seguinte trecho: “[...] a constituição da identificação étnico-racial na infância não tem sido o foco de estudos no Brasil. São poucas as pesquisas que privilegiam as crianças como atores sociais em condições de explicitar sua compreensão sobre seu pertencimento étnico-racial" (TRINIDAD, 2016, p. 1, grifos dos autores).
} 
- O reconhecimento de que as pessoas podem ser brancas ou negras, desenvolve-se por volta dos três e quatro anos de idade.

- As crianças negras ou brancas só se reconhecem como membros de um desses grupos após os três anos de idade.

- A predisposição para se identificar como "branca" desenvolve-se, em geral, após o contato com indivíduos de grupos étnicos diferentes daqueles a que a criança pertence.

Bento (2012, p. 101), ao fazer uma revisão bibliográfica de estudos realizados em maior parte no Brasil sobre identidade racial na educação infantil, constata que algumas afirmações se repetem, como:

- muito cedo elementos da identidade racial emergem na vida das crianças; diferentes autores destacam que, entre 3 e 5 anos a criança já percebe a diferença racial e, ao percebê-la, interpreta e hierarquiza;

- crianças pequenas são particularmente atentas ao que é socialmente valorizado ou desvalorizado, percebendo rapidamente o fenótipo que mais agrada e aquele que não é bem aceito;

- crianças pequenas brancas se mostram confortáveis em sua condição de brancas e raramente explicitam o desejo de ter outra cor de pele ou outro tipo de cabelo;

- crianças pequenas negras se mostram desconfortáveis em sua condição de negras, porém raramente reagem à colocação de que preto é feio. Crianças negras revelam o desejo de mudar o tipo de cabelo e a cor da pele;

- a criança negra parece mais agudamente atenta à diferença racial do que a branca.

Para Abramowicz e Oliveira (2012) é preciso pensar de quais formas e de quais aspectos as crianças negras se apropriam do contexto no qual elas vivem. No caso do cenário brasileiro, marcado pelo processo de escravização, exclusão, criminalização e discriminação dos sujeitos negros, defendem que é preciso:

[...] pensar outras e novas formas de socialização para a produção de novas crianças e outras infâncias, no sentido de pensar outra forma de educação com crianças pequenas que podem ser informadas a partir de uma sociologia da infância que aborde aspectos de nossa realidade social, cultural, econômica e, sobretudo, racial (ABRAMOWICZ, OLIVEIRA, 2012, p. 62).

Assim, a possibilidade de que as crianças negras construam positivamente suas identidades têm estreita relação com o rompimento no campo teórico / prático da desigualdade de distribuição de posicionamento, de espaços e de valorização entre crianças de classes e de grupos étnico-raciais distintos.

Os conhecimentos sobre os processos de socialização e de construção da identidade étnicoracial na infância e as preocupantes constatações feitas por pesquisadoras do campo da educação infantil, no que diz respeito à presença da discriminação étnico-racial no cotidiano de creches e pré-escolas urbanas, nos levaram a indagar sobre como esses processos se dão nas e entre as crianças negras que vivem em contextos não urbanos, como o quilombola ${ }^{2}$, ambiente no qual não

\footnotetext{
2 “Comunidades quilombolas são grupos com trajetória histórica própria, cuja origem se refere a diferentes situações, a exemplo de doações de terras realizadas a partir da desagregação de monoculturas; compra de terras pelos próprios sujeitos, com o fim do sistema escravista; terras obtidas em troca da prestação de serviços; ou áreas ocupadas no
} 
há uma maioria branca e, hipoteticamente, a discriminação não estaria tão presente. Nesse contexto, surgiu a seguinte questão: quais são os fatores que perpassam a socialização étnico-racial de crianças negras remanescentes de quilombolas no contexto da educação infantil?

Um levantamento feito na Biblioteca Digital de Teses e Dissertações (BDTD), sem delimitação de um período, com a palavra-chave crianças quilombolas, resultou em 40 produções. A partir da leitura dos resumos, foram selecionados quatro trabalhos (LEITE, 2009; MACÊDO, 2008; PAULA, 2014; SOUZA, 2015), tendo em vista a participação de crianças menores de seis anos e a realização da pesquisa, mesmo que parcialmente, em espaços de educação formal. Essas pesquisas tiveram como locus os espaços frequentados pelas crianças negras remanescentes de quilombolas, por exemplo, os quintais das casas, os centros religiosos, os espaços culturais, os riachos, as escolas (predominantemente urbanas) etc. As pesquisadoras acompanhavam as crianças em suas vivências na comunidade, não restringindo-se às experiências vividas na escola. A seguir, apresentamos elementos importantes de cada um desses trabalhos.

Ao realizar uma pesquisa que objetivou compreender como o currículo escolar influencia no processo de construção da identidade étnico-racial da criança quilombola ${ }^{3}$, refletindo sobre a relação identidade e autoestima, Macêdo (2008) teve como locus de pesquisa uma instituição urbana que atendia crianças de três a seis anos de idade numa comunidade de remanescentes de quilombolas. A partir da aplicação de uma dinâmica com o uso de espelho e escuta das crianças, a autora constatou que a maioria das crianças se reconheciam como negras, manifestando autorrepresentação positiva de si mesmas.

Paula (2014), em pesquisa também realizada com crianças de pré-escola, objetivou analisar as relações que crianças negras moradoras de uma comunidade quilombola estabeleciam com crianças não negras do meio urbano, em uma instituição de educação infantil localizada fora da comunidade. Nos resultados apresentados por ela, chama muita atenção a solidariedade que havia entre as crianças quilombolas, especialmente quando elas eram alvo de discriminação: "[...] as relações concretas de limites e constrangimentos que vivenciam, em especial na escola, são superadas tendo como base a constituição de seu grupo de pertença identitária" (PAULA, 2014, p. 249). Além disso, as crianças demonstravam autoestima e autoimagem positivas, o que era evidenciado nos comportamentos de reação aos insultos sofridos por elas por parte das crianças brancas da escola. As meninas negras valorizavam os adornos que eram usados nos penteados feitos pelas suas mães e os meninos, por saberem passos de capoeira, eram invejados por parte das outras crianças da turma.

Leite (2009) buscou investigar a visão de crianças negras quilombolas sobre a construção identitária. A pesquisa, realizada em uma escola localizada no meio urbano, contou com a participação de crianças da pré-escola, na faixa etária de cinco e seis anos. A pesquisadora constatou que as crianças manifestavam o desejo de que elas e seus familiares fossem brancos, que elas concebiam a pele preta como feia e faziam uso de expressões que amenizavam a identificação étnico-racial (por exemplo, se diziam morenas clara ou escura) ou que iam de encontro a ele (crianças que diziam ter a cor azul como cor da pele). Leite (2009) ainda identificou que as crianças se mostravam descontentes com o cabelo crespo, desejando ter cabelo liso. Contudo, a pesquisadora ressalta que as crianças manifestavam encantamento pelas tradições da comunidade na qual moravam, uma vez que, nos dias de festas, quando elas se adornavam para participar, as pessoas "de fora" tiravam fotos e olhavam para elas com admiração.

processo de resistência ao sistema escravista. Em todos os casos, o território é a base da reprodução física, social, econômica e cultural da coletividade". Disponível em https://www.mdh.gov.br/navegue-por-temas/igualdaderacial/artigos-igualdade-racial/comunidades-quilombolas. Acesso em 14 jan. 2020.

${ }^{3}$ As pesquisas analisadas se referem aos sujeitos da investigação como "crianças quilombolas". No presente estudo, se adota a referência que é feita nos documentos oficiais, ou seja, "crianças remanescentes de quilombolas".

Revista Teias v. 21 • n. 62 • jul./set. 2020 • Seção Temática Raça e Cultura 
As crianças quilombolas pertencentes à faixa etária da educação infantil, atendidas em meio urbano, foram também sujeitos da pesquisa de Souza (2015, p. 10), que buscou entender a produção da identidade negra nessas crianças, especificamente, como a sua elaboração é influenciada pela pertença a um grupo quilombola. Os dados construídos e analisados pela pesquisadora a levaram a afirmar que o pertencimento étnico-racial das crianças envolvia "[...] um trânsito entre aceitar-se e rejeitar-se, denunciando experiências de exclusão caracterizadas pela discriminação racial e o racismo, concomitantes à afirmação do lugar onde vivem, um lugar de quilombolas".

Como é possível perceber, há aproximações entre as investigações realizadas com crianças negras remanescentes de quilombolas: as instituições locus das pesquisas são em maior parte do meio urbano e, com frequência, as investigações se deram com crianças da pré-escola, o que pode sinalizar que ainda pouca atenção é dada aos bebês e às crianças bem pequenas quando o assunto é o processo de socialização étnico-racial, mas também que esses sujeitos, no caso, moradores do campo, ainda são excluídos, em sua maioria, de espaços coletivos de educação e cuidado, sobretudo na própria comunidade. A análise dessas pesquisas indica que a discriminação étnico-racial está presente na vivência educativa dessas crianças e que há maior aceitabilidade e bem-estar em relação ao pertencimento étnico-racial em crianças remanescente de quilombolas, como também condutas de denúncia e defesa em relação a situações de discriminação vividas.

As práticas que compõem as rotinas vivenciadas por crianças negras remanescentes de quilombolas nesses territórios possivelmente lhes fornecem possibilidades de interação e apropriação do patrimônio cultural de seus ascendentes, das negras e dos negros que lhes antecederam. Por isso, essas práticas sociais e de linguagens constituem-se como espaços de negociações, pois há pluralidade cultural e de identidades nesses territórios, que foram se constituindo a partir de uma história própria. A presente pesquisa teve por objetivo analisar as interações com colegas de turma vivenciadas por crianças negras remanescentes de quilombolas que frequentam creche na própria comunidade, com foco nas implicações de possíveis processos de identificação étnico-racial nessas interações.

\section{A ABORDAGEM TEÓRICO-METODOLÓGICA DO ESTUDO}

A presente investigação teve como locus de investigação um Centro de Educação Infantil (CEI) público, localizado no interior de uma comunidade de remanescentes de quilombolas da região metropolitana de Fortaleza (Ceará). Vale ressaltar que a localização da instituição foi o principal critério utilizado para a sua seleção, tendo em vista o objetivo da pesquisa. A faixa etária contemplada também foi um critério de escolha do locus do estudo, uma vez que as outras pesquisas investigaram, majoritariamente, crianças pequenas (quatro anos a cinco anos e onze meses).

O Centro de Educação Infantil enfocado nesta pesquisa tinha 12 turmas de crianças de três a cinco anos, em horário parcial. $\mathrm{O}$ agrupamento no qual a pesquisa foi realizada, denominado Infantil III, contava com uma professora A (parda) e uma professora B (branca) ${ }^{4}$, que substituía a primeira nos chamados "dias de planejamento"

O agrupamento era composto por 15 crianças de três a quatro anos, com predominância de crianças negras (pretas e pardas): seis eram pretas, seis eram pardas e três eram brancas. Os seus nomes são fictícios, resguardando, dessa maneira, o direito ao anonimato.

\footnotetext{
${ }^{4}$ A atribuição da identificação étnico-racial dos sujeitos foi feita pelos pesquisadores.

${ }^{5}$ Seguindo o disposto na Lei do Piso Salarial Nacional dos Professores (Lei n. 11.738), um terço do tempo de cada professor deve ser dedicado a atividades didáticas fora da sala de aula.
} 
Foram realizadas oito observações participantes de turnos inteiros, de sete às onze horas da manhã. Durante as observações, foram produzidos registros em diário de campo e fotografias. Esse procedimento foi realizado em maior volume na sala de referência da turma, mas incluiu os outros espaços da instituição também utilizados ao longo da rotina das crianças.

\section{A SOCIALIZAÇÃO ÉTNICO-RACIAL POR / ENTRE CRIANÇAS NEGRAS BEM PEQUENAS REMANESCENTES DE QUILOMBOLAS NO CONTEXTO DE CRECHE}

A socialização entre crianças negras, com foco no processo de identificação étnico-racial, pode ser compreendida como um período legítimo para a apropriação, interpretação, negociação e produção de mensagens étnico-raciais, as quais têm seus sentidos e significados influenciados pelo contexto social dos sujeitos, o familiar, o comunitário, o escolar etc. Essas mensagens são apropriadas pelas crianças a partir de características específicas e exclusivas do modo como interagem e apreendem a realidade, tendo em visto o movimento predominante de olhar para si que marca esse período da vida, na visão da psicogenética walloniana.

O objetivo do presente trabalho foi analisar as interações vivenciadas por crianças negras remanescentes de quilombolas que frequentam creche na própria comunidade, com foco nas implicações de possíveis processos de identificação étnico-racial nessas interações, isto é, se as suas interações eram influenciadas pela percepção das diferenças de cor de pele, de tipo de cabelo etc.

Os dados construídos na pesquisa de campo foram organizados em dois grupos de interações. O primeiro, Grupo I, diz respeito às interações nas quais há comportamentos amistosos entre crianças negras e brancas e o segundo, Grupo II, reúne as interações nas quais há conflitos entre elas.

As interações amistosas entre as crianças negras e brancas eram marcadas pelo acolbimento, pelo compartilhamento, pela brincadeira e pela defesa do outro em conflitos.

As relações amistosas manifestadas em sala também eram vivenciadas entre crianças pardas e pretas, as quais compunham a maior parcela desse agrupamento. Como exemplo, certo dia, Jesus (pardo) estava sentado perto de Nízia (preta) e toca, com cuidado, uma ferida localizada na perna da menina (o ferimento havia sido percebido pela professora logo que a menina chegou na escola, quando disse para a menina ter cuidado para não o machucar). Tendo em vista o objetivo do trabalho, a seguir serão enfocadas apenas as interações entre crianças negras e brancas.

O acolhimento foi presenciado, por exemplo, numa situação em que Aurora, menina branca, consolou Maria, menina parda, após uma repreensão da professora:

A professora guarda um brinquedo que estava com Maria. Ela começa a chorar. Aurora, que está perto dela, diz "Não chora não!" e passa a mão na sua cabeça (Diário de campo, 22 fev. 2017).

Em outro momento da rotina, também foi presenciada outra manifestação de carinho por parte de Aurora para com Maria, quando a primeira deu um abraço demorado na segunda (Diário de campo, 7 abr. 2017). Além dessas manifestações, outras indicavam companheirismo entre essas meninas e entre elas e outras crianças, tanto brancas como negras, com as quais compartilhavam muitos momentos da rotina.

Foram presenciadas várias manifestações de compartilhamento entre crianças negras e brancas, como, por exemplo, quando José, menino branco, compartilhou a água de sua garrafa com Inácio, menino preto (Diário de campo, 29 mar. 2017).

As brincadeiras também constituíam momentos em que crianças negras e brancas participavam mutuamente das experiências umas das outras. Essas situações foram observadas em 
vários momentos da rotina do grupo, tanto na sala de referência, como no parque da instituição. Alguns exemplos:

José (branco) utiliza um disco de madeira como sabonete para passar em Nízia (preta). Em seguida, a enxuga com a toalha (Diário de campo, 5 abr. 2017).

Nízia (preta) brinca em um balanço com uma menina loira e branca. Depois, brinca com crianças mais velhas no balanço, tanto negras como brancas (Diário de campo, 10 abr. 2017)

José (branco) fica muito tempo brincando com Rosa (preta), fazendo construções com formas geométricas de madeira (Diário de campo, 10 abr. 2017)

Os momentos de conflitos no agrupamento investigado também envolviam comportamentos de defesa das crianças neles envolvidas. Vale ressaltar que foram observadas situações de conflito em que crianças negras defenderam crianças brancas e igualmente crianças brancas defenderam crianças negras, tanto meninas quanto meninos:

Galvão (pardo) bate em Aurora (branca). Graça (parda) diz: "Não bate na minha irmã" (Diário de campo, 29 mar. 2017).

José (branco) defende Caetano (preto) de Aurora (branca) e Maria (parda) quando eles disputam uma corda: as meninas pegam a corda das mãos de Caetano, que estava brincando de fazer "cobrinha", deslizando a corda no chão, de modo que ela se movimentava da forma como a cobra rasteja. Em seguida, José pega a corda das meninas e a devolve para Caetano (Diário de campo, 24 fev. 2017).

É plausível supor, portanto, que as interações amistosas entre as crianças negras e brancas do agrupamento enfocado pareciam não sofrer implicações das diferenças de cor de pele, tipo de cabelo ou por outras marcas fenotípicas das crianças pardas e pretas. $\mathrm{O}$ fenótipo das crianças parecia não ser levado em conta nas ações e comportamentos das crianças brancas ou negras. As questões afetivas parecem predominar nas interações do grupo, ou seja, as crianças defendiam aquelas com as quais tinham algum tipo de relacionamento (caso de Graça, que considera Aurora sua irmã, e José parece se identificar com Caetano, tomando partido dele na disputa pela corda com as duas meninas), assim como compartilhavam objetos e brincavam com aqueles colegas com quem tinham preferências semelhantes, umas por brincadeiras mais agitadas, outras por brincadeiras que envolviam materiais, outras ainda pelo gosto de estarem sempre conversando. Tal suposição se fortalece quando é considerada a possibilidade de as três crianças brancas da turma interagirem somente entre si, caso elas tivessem alguma dificuldade de relacionamento com as crianças negras e não possuíssem interesses e afetos em comum com as demais colegas.

Como já referido, as interações de conflitos entre as crianças negras e brancas constituem o Grupo II. Elas foram presenciadas em quase todas as rotinas observadas e, com frequência, envolviam o menino Caetano (preto). Ele era alvo de ordens e / ou recusas por parte de crianças brancas e pardas, como exemplificado nos trechos abaixo:

Aguiar (branco) derruba o material no chão. Caetano (preto) está do lado, recolhe e entrega para Aguiar. Aguiar repete a ação. Caetano olha e não recolhe. Aguiar fica irritado (Diário de campo, 22 fev. 2017).

Caetano (preto) pergunta o que Aurora (branca) trouxe para lanchar. Ela continua segurando o recipiente em que está o seu lanche e não responde à pergunta do menino (Diário de campo, 24 fev. 2017).

Aurora (branca) e Maria (parda) não deixam Caetano brincar com elas, mas acolhem Jesus (pardo) na brincadeira (Diário de campo, 24 fev. 2017). 
Nas primeiras rotinas observadas, Caetano parecia ser uma criança que assumia um papel de subordinação em relação às outras crianças, sobretudo às crianças brancas. Contudo, não foi possível constatar a continuidade desse comportamento ao longo da pesquisa, pois o menino foi transferido para o turno da tarde. Por outro lado, a conduta de José, uma das crianças brancas que intimidava Caetano, se estendeu durante todo o trabalho de campo e repercutiu nos seus contatos com outras crianças negras, por exemplo, com Tereza:

Em uma situação de brincadeira, Tereza (parda) diz que é a vez dela. José (branco) faz uma expressão facial de repreensão para a menina. Tereza (negra) parece ficar intimidada e deixa outra criança tomar o seu lugar. (Diário de campo, 9 mar. 2017).

Embora José manifestasse muitos comportamentos agressivos, predominantemente com as meninas negras, não foi possível identificar se esse comportamento tinha alguma relação com o fato de elas serem pretas e pardas ou por outros traços fenotípicos, pois a única menina branca na turma (em que havia seis meninas negras) também era alvo de suas grosserias. Tais comportamentos de José, mesmo que em menor medida, também constituíam as interações do garoto com os meninos negros da turma, nos quais ele batia e intimidava. No entanto, não se pode afirmar que o pertencimento étnico-racial desses meninos fosse determinante para essas agressões, uma vez que o outro menino branco da sala, Aguiar, também era intimidado por José. Portanto, ele também agredia seus únicos colegas brancos, tanto menina como menino.

Vale mencionar também que José sempre levava objetos de uso pessoal para a escola, os quais pareciam ser percebidos pelas outras crianças como novidades que as atraía, tais como brinquedos, óculos, bonés, pulseiras etc. Em uma das situações observadas, José exibiu seus adereços da seguinte forma:

José (branco) coloca óculos escuros, um chapéu com desenho do Mickey e uma pulseira amarela e vai se exibir para Inácio (preto). Depois, aperta a mão de Bernardo (pardo), como um gesto de cumprimento (Diário de campo, 23 mar. 2017).

Diferentemente das condutas de agressão e intimidação, esse comportamento de José mais parecia uma manifestação de exibição, pois, além de colocar os adereços, o menino andava de um modo diferente, parecia ter um andar mais solto, no qual a coluna é flexionada e os braços ficam como que relaxados. Os meninos negros da turma não levavam objetos como os de José para a creche durante o período observado, o que talvez pudesse causar um sentimento de superioridade no menino branco e de inferioridade nos meninos negros.

Contudo, nenhum comportamento discriminatório foi manifestado no decorrer da pesquisa de campo, pelo contrário, o relacionamento de José com os meninos negros foi se tornando amigável, passaram a realizar combinados e favores entre si. Por outro lado, não é possível afirmar que esses novos comportamentos eram fruto de uma reciprocidade entre as crianças, pois também pareciam ser influenciados pelas constantes agressões de José, as quais tinham como consequência condutas condescendentes por parte dos meninos negros.

Isso pode ser observado, por exemplo, na ocasião em que Inácio (negro) quis entregar para José um depósito no qual o colega havia trazido o seu lanche para a creche e que havia deixado no refeitório e José pediu para que Inácio o guardasse na sua bolsa. Essa situação causou tanto desconforto no pesquisador que ele disse "José, vai lá guardar" e pediu para Inácio entregar o depósito para José. Contudo, nenhuma das crianças atendeu esse pedido; ao contrário, José disse novamente para Inácio guardar o depósito na bolsa dele e assim o menino fez (Diário de campo, 5 abr. 2017). Dessa forma, a manutenção do pedido de José a Inácio, mesmo frente à sugestão de 
um adulto, reforça a possibilidade levantada anteriormente: havia tanto um relacionamento de reciprocidade como de condescendência (ou até submissão) por parte dos meninos negros.

Vale mencionar que Inácio era uma criança muito receptiva e simpática, que gostava de estar com as outras crianças da turma. Tendo em vista essas características, é provável que entre ele e José tenha se constituído um relacionamento de dominação e condescendência, já que foi observada uma conduta mais ríspida e rígida no menino branco e uma mais sociável e flexível no menino negro. É possível afirmar que, passado o período de adaptação àquele ambiente de vida coletiva, as crianças começavam a consolidar alguns relacionamentos, tornando-os mais estáveis.

No agrupamento enfocado, as interações que envolviam conflitos pareciam ter origem no próprio processo de adaptação das crianças a um ambiente coletivo de vida, que envolvia, por exemplo, a disputa de materiais e a submissão do desejo individual à ordem coletiva. Vale acrescentar que Aquino e Cruz (2019) discutiram a percepção de crianças de três e quatro anos moradoras de uma comunidade de remanescentes quilombola sobre os elementos da aparência (cor da pele e outros traços corporais de identificação étnico-racial), com base em entrevistas coletivas com as crianças utilizando pares de fotografias de meninas e meninos negras/os e brancas/os de diferentes idades. Os autores concluíram que as possibilidades de identificar diferenças de cor da pele e outros traços corporais e atribuir qualidades a pessoas negras encontrava-se em desenvolvimento na maioria das crianças, o que reforça a hipótese de que as percepções das diferenças de cor de pele, de tipo de cabelo etc. não eram definidoras nas interações entre as crianças ora enfocadas.

Como citado anteriormente, a socialização étnico-racial vivenciada por crianças, na faixa etária de quatro a seis anos, remanescentes de quilombolas em diversas regiões do país, é marcada pela reprodução de estereótipos da imagem do negro ou, em medida bem menor, pela promoção de um orgulho racial e étnico. Em contrapartida a essas duas tendências, as interações entre as crianças da turma investigada, de três a quatro anos, pareciam não possuir conteúdos étnico-raciais nítidos, o que pode decorrer das experiências que as crianças viveram até então e das especificidades de acesso à realidade possíveis a elas nesse período da primeiríssima infância, como discutido na introdução desse trabalho.

Além das especificidades da vivência da infância, é preciso acrescentar que nessa turma não eram possibilitados contatos com elementos históricos e atuais da comunidade negra e campesina à qual pertenciam, como com artefatos, contos e brincadeiras. Os espaços da instituição, por exemplo, eram ornamentados com representações brancas (estereótipos nórdicos) e com poucas representações negras, sendo estas predominantemente caricaturescas; e nenhum artefato cultural da comunidade foi identificado entre os materiais da instituição.

Entre tais características da proposta pedagógica descritas acima e a socialização familiar, que foi possível conhecer ${ }^{6}$, parecia haver uma estreita relação. Assim como na escola, a socialização promovida pelas famílias parecia oferecer às crianças mensagens de orgulho racial e étnico branco. Isso foi inferido a partir da predominância da presença da cultura de massa, ou seja, às crianças eram dados produtos com representações estereotipadas de personagens de filmes veiculados na publicidade destinada à clientela infantil. Assim, as imagens de bonecas brancas, loiras ou ruivas, magérrimas, de olhos claros etc. destoava vergonhosamente das meninas negras que eram suas usuárias.

Por outro lado, também foi percebido que as famílias tinham preocupação quanto à aparência das crianças. Principalmente as meninas iam bem arrumadas e penteadas. Em especial,

\footnotetext{
${ }^{6}$ Os dados em relação às famílias são quanti e qualitativamente menores, já que o ambiente familiar das crianças não se constituiu como objeto de estudo desta investigação. Os dados foram inferidos a partir de conversas e do tipo de materiais e vestimentas usados pelas crianças, adquiridos pelas famílias.
} 
Nízia fazia sucesso entre as crianças e as mães, quando ia para o CEI com penteado de trancinhas. Dessa forma, realçava um componente do seu pertencimento, pois, como afirma Gomes (2010, p. 24 apud PAULA, 2014, p. 238), “[...] o cuidado com a estética, a força dos penteados afros é uma forma de expressar beleza, divulgar a riqueza do universo afro-brasileiro e a força ancestral que nos move no Brasil".

Em estudo que revelou práticas pedagógicas e parentais de socialização de orgulho racial e étnico negro, diferentes da maioria das que foram aqui discutidas, Macêdo (2008) afirma que:

[...] a preocupação da escola em trabalhar [as relações étnico-raciais] com essas crianças da educação infantil parece revelar que já são respostas da cobrança das lideranças locais e dos pais dos alunos/as, principalmente aqueles que já têm um papel mais atuante na luta da comunidade, bem como aqueles que participam das reuniões da associação (MACÊDO, 2008, p. 122).

Segundo uma das líderes do território investigado, que também compunha a gestão do CEI locus da pesquisa, a comunidade caminhava para a construção de estratégias de preservação da cultura, como também de contágio dos que nela residiam para a promoção de um sentimento de ser descendente e herdeiro de "[...] um negro forte e corajoso, que ressignificou o seu refúgio (da escravidão sofrida) como lugar de alegria". Dessa forma, parece que tal processo de identidade individual, coletiva e política, em construção, era visualizado na educação e cuidado que as famílias e a escola tinham para com suas crianças bem pequenas.

\section{CONSIDERAÇÕES FINAIS}

O presente estudo foi realizado com crianças negras bem pequenas remanescentes de quilombolas e sua professora numa instituição de Educação Infantil localizada numa comunidade de remanescentes quilombolas na região metropolitana de Fortaleza (Ceará).

Foi possível perceber que nessa instituição e nas famílias pouca (ou quase nenhuma) atenção era dada ao pertencimento étnico-racial das crianças, no sentido de fomentar o sentimento de pertencimento à comunidade em que viviam. Além disso, implicitamente, ofereciam a elas algumas mensagens de orgulho racial branco, ou seja, de valorização do estereótipo claro, de cabelo loiro, de olhos claros etc., nos materiais escolares, vestimentas e acessórios usados pelas crianças. Assim, no mínimo, não contribuíam para o processo das crianças de "tornarem-se negras" e terem orgulho disso.

Não foi percebido nas observações realizadas comportamentos racistas por parte da professora, apesar da ausência dos negros nos livros de literatura, nos brinquedos e na decoração da sala evidenciarem uma discriminação velada. Ela também parecia ignorar a identificação étnicoracial das crianças em sua atuação. Durante o período de pesquisa não se constatou nenhuma contribuição sua à construção identitária das crianças em diálogo com o grupo étnico-racial negro e com a comunidade remanescente de quilombolas como um componente das suas interações e práticas com a turma.

Centrando-se no objetivo desse trabalho, é possível afirmar que os elementos da aparência dessas crianças negras (cuja percepção e atribuição de sentido encontrava-se em desenvolvimento na maioria delas), como cor de pele, formato do nariz e dos lábios e tipo do cabelo pareciam não ter importância determinante nas interações entre elas e as crianças brancas. As características de pensamento infantil e o pequeno número de experiências vividas até então são fatores que precisam ser considerados para compreender esta constatação. Em relação aos processos de identificação étnico-racial, possivelmente as experiências que as crianças já tinham vivido não foram marcantes para dar-lhes um forte colorido. 


\section{REFERÊNCIAS}

ABRAMOWICZ, Anete; OLIVEIRA, Fabiana de. As relações étnico-raciais e a sociologia da infância no Brasil: alguns aportes. In: BENTO, Maria Aparecida Silva (org.). Educação infantil, igualdade racial e diversidade: aspectos jurídicos, políticos e conceituais. São Paulo: Centro de Estudos das Relações de Trabalho e Desigualdades - CEERT, 2012, v. 1, p. 47-61.

AQUINO, Pedro Neto Oliveira de; CRUZ, Silvia Helena Vieira. A percepção de crianças de uma turma de creche acerca do pertencimento étnico-racial, numa comunidade de remanescentes de quilombolas. In: $39^{a}$ Reunião Nacional da Anped. Niterói. Anais da $39^{a}$ Reunião Nacional da Anped. Niterói, 2019.

BENTO, Maria Aparecida Silva. A identidade racial em crianças pequenas. In: BENTO, Maria Aparecida Silva (org.). Educação infantil, igualdade racial e diversidade: aspectos jurídicos, políticos e conceituais. São Paulo: Centro de Estudos das Relações de Trabalho e Desigualdades - CEERT, 2012, v. 1, p. 98-114.

BERGER, Peter L.; LUCKMANN, Thomas. A construção social da realidade. Petrópolis: Vozes, 1974. CORSARO, William A. Sociologia da infância. 2. ed. Porto Alegre: Artmed, 2011.

LEITE, Gisélia Maria Coelho. Políticas públicas e olbares sobre a diferença: a criança quilombola na instituição escolar e em outros espaços educativos de lagoa Trindade (Jequitibá - MG). Dissertação (Mestrado em Educação). Pontifícia Universidade Católica de Minas Gerais, Belo Horizonte, 2009. MACÊDO, Dinalva de Jesus Santana. O curriculo escolar e a construção da identidade étnico-racial da criança $e$ do adolescente quilombola: um olhar reflexivo sobre a autoestima. Dissertação (Mestrado em Educação). Universidade do Estado da Bahia, Salvador, 2008.

MEDEIROS, Marília Salles Falci. A construção teórica dos conceitos de socialização e identidade. Revista de Ciências Sociais. v. 33, n. 1, p. 78-96. Programa de Pós-Graduação em Sociologia da UFC, 2002.

PAULA, Eliane de. “Vem brincar na rua!” Entre o quilombo e a Educação Infantil: capturando expressões, experiências e conflitos de crianças quilombolas no entremeio desses contextos. Tese (Doutorado em Educação). Universidade Federal de Santa Catarina, Florianópolis, 2014.

OLIVEIRA, Fabiana de. Um estudo sobre a creche: o que as práticas pedagógicas produzem e revelam sobre a questão racial? Dissertação de Mestrado - Universidade Federal de São Carlos, São Carlos, 2004.

SARMENTO, Manuel Jacinto. Sociologia da infância: correntes e confluências. In: SARMENTO, Manuel Jacinto; GOUVEA, Maria Cristina Soares (org.). Estudos da infância: educação e práticas sociais. Petrópolis, Rio de Janeiro: Vozes, 2008. p. 17-39.

SILVA, Petronilha Beatriz Gonçalves e. Crianças negras entre a assimilação e a negritude. In: Revista Eletrônica de Educação. v. 9, n. 2, 2015, p. 161-187.

SOUZA, Márcia Lúcia Anacleto de. "Ser quilombola": identidade, território e educação na cultura infantil. Tese (Doutorado) - Faculdade de Educação, Universidade Estadual de Campinas. São Paulo, 2015.

TRINIDAD, Cristina Teodoro. Diversidade étnico-racial: por uma prática pedagógica na educação infantil. In: BENTO, Maria Aparecida Silva (org.). Educaşão infantil, igualdade racial e diversidade: aspectos políticos, jurídicos, conceituais. São Paulo: Centro de Estudos das Relações de Trabalho e Desigualdades - CEERT, 2012. 
TRINIDAD, Cristina Teodoro. Construção da Identidade étnico-racial: o que as crianças préescolares têm a dizer? In: VIII Fórum Internacional de Pedagogia, 2016, Imperatriz - MA. VIII Fórum Internacional de Pedagogia, 2016.

WALLON, Henri. A evolução psicológica da criança. São Paulo: Martins Fontes, 2007.

WALLON, Henri. A evolução psicológica da criança. Portugal: Edições 70, 1995.

Submetido em fevereiro 2020 Aprovado em junbo 2020

\section{Informações do(a) autor(a)}

Pedro Neto Oliveira de Aquino

Pós-graduando em Educação Brasileira na Universidade Federal do Ceará

E-mail: pedrooliveiraaquino@outlook.com

ORCID: https://orcid.org/0000-0003-4624-3860

Link Lattes: http://lattes.cnpq.br/2799418103208208

Silvia Helena Vieira Cruz

Professora Titular da Universidade Federal do Ceará, Departamento de Estudos Especializados E-mail: silviavc@uol.com.br

ORCID: https://orcid.org/0000-0002-3406-3005

Link Lattes: http://lattes.cnpq.br/4232760913140402 